\title{
Deteç̧ão de soja pelo teor de isoflavonas em lombo injetado de suíno
}

\author{
Detection of soy by analysis of isoflavones in enhanced pork loin \\ Heitor Daguer $^{\mathrm{I}^{*}}$ Luciano dos Santos Bersot $^{\mathrm{II}}$ Sidney Pacheco ${ }^{\mathrm{III}}$ \\ Ronoel Luiz de Oliveira Godoy ${ }^{\text {II }}$
}

- NOTA -

\section{RESUMO}

No presente trabalho, a utilização de $1,5 \%$ de proteína isolada de soja em lombo de suíno foi detectada por meio do teor de isoflavonas, utilizando-se cromatografia líquida de alta eficiência. Elegeu-se o pico de genistina para quantificação, construindo-se uma curva-padrão com a proteína isolada de soja utilizada nas salmouras para injeção das carnes. A técnica revelou-se como uma alternativa rápida e eficaz para ser implantada no controle da utilização desse ingrediente em produtos cárneos.

Palavras-chave: cromatografia, proteína de soja, isoflavonas, produtos cárneos.

\section{ABSTRACT}

The present research aimed to detect the use of soy protein isolate $(1.5 \%)$ in enhanced pork loins through isoflavones identification, using high performance liquid chromatography (HPLC). The genistine peak has been chosen for the soy quantification, and it has been correlated with a standard curve built with the soy protein isolate used for the preparation of brines which have been injected into meat. Identification of isoflavones with HPLC is an efficient technique for the detection of soy in meat products.

Key words: chromatography, soy protein, isoflavones, meat products.
A autenticidade dos produtos de origem animal tem sido motivo de preocupação constante para a fiscalização de alimentos, sobretudo o controle do emprego de proteínas não cárneas e outros ingredientes utilizados rotineiramente na industrialização de carnes. Embora a soja seja um dos ingredientes vegetais mais utilizados em produtos cárneos, o controle analítico de sua utilização ainda se constitui um problema, em razão da falta de sensibilidade de algumas técnicas. Outras proteínas, como as do soro de leite, podem ser detectadas por técnicas como a eletroforese; no entanto, no caso da soja, nem sempre ocorre a separação adequada (DAGUER et al., 2010).

Em carnes, a ocorrência de isoflavonas deriva exclusivamente da adição de condimentos ou outros ingredientes vegetais, pois estas são produtos do metabolismo secundário de algumas espécies de plantas, sobretudo de algumas leguminosas, como a soja, o amendoim, a lentilha e a ervilha (MELLENTHIN \& GALENSA, 1999; KUHNLE et al., 2008).

As isoflavonas são compostos fenólicos bioativos predominantemente encontradas em leguminosas, possuindo diversas atividades biológicas, as quais parecem estar relacionadas com as suas estruturas químicas (GENOVESE \& LAJOLO,

\footnotetext{
IMinistério da Agricultura, Pecuária e Abastecimento. Laboratório Nacional Agropecuário. Serviço Laboratorial Avançado em Santa Catarina. Rua João Grumiché, 117, 88102-600, São José, SC, Brasil. E-mail: heitor.daguer@agricultura.gov.br. *Autor para correspondência.

IIPrograma de Pós-graduação em Tecnologia de Alimentos, Universidade Federal do Paraná (UFPR). Centro Politécnico, Curitiba, PR, Brasil.

IIIMinistério da Agricultura, Pecuária e Abastecimento. Empresa Brasileira de Pesquisa Agropecuária, EMBRAPA Agroindústria de Alimentos, Rio de Janeiro, RJ, Brasil.
} 
2001). Apresentam-se em quatro estruturas químicas, perfazendo 12 substâncias: (i) as agliconas daidzeína, genisteína e gliciteína; (ii) seus respectivos $\beta$ glicosídeos daidzina, genistina e glicitina; (iii) os derivados glicosilados acetilados 6"-O-acetildaidzina, 6"-O-acetilgenistina, 6"-O-acetilglicitina e (iv) os derivados glicosilados malonilados 6"-Omalonildaidizina, 6"-O-malonilgenisteína e 6"-Omalonilglicitina (CESAR et al., 2007).

O presente trabalho teve por objetivo detectar a proteína isolada de soja (PIS) utilizada em lombos de suíno injetados com $15 \%$ de diferentes salmouras, por meio da determinação do teor de isoflavonas por cromatografia líquida de alta eficiência.

Utilizando-se uma máquina injetora de salmoura, os lombos foram injetados com água e $0,75 \%$ de sal (tratamento II); água, $0,75 \%$ de sal e $0,45 \%$ de tripolifosfato de sódio (tratamento III); água, $0,75 \%$ de sal e $1,5 \%$ de proteína isolada de soja (tratamento IV); água, $0,75 \%$ de sal e $1,5 \%$ de concentrado proteico de soro de leite (tratamento V); água, $0,75 \%$ de sal, $0,45 \%$ de tripolifosfato de sódio e $1,5 \%$ de proteína isolada de soja (tratamento VI) e água, $0,75 \%$ de sal, $0,45 \%$ de tripolifosfato de sódio e $1,5 \%$ de concentrado proteico de soro de leite (tratamento VII). O tratamento I correspondeu ao lombo não injetado (in natura). Após injeção, os lombos foram embalados a vácuo e mantidos sob refrigeração.

As análises foram realizadas no Laboratório de Cromatografia Líquida da EMBRAPA Agroindústria de Alimentos. Toda a água utilizada durante as análises cromatográficas foi de grau ultrapuro, recém-coletada em equipamento Milli-Q ${ }^{\circledR}$ (Millipore Ltd., EUA), com resistividade mínima de $18 \mathrm{M} \Omega / \mathrm{cm}$ e carbono orgânico total (TOC) máximo de $7 \mathrm{ppb}$. Todos os solventes utilizados foram de grau HPLC (Tedia Company, Inc., EUA).

As amostras de lombo foram trituradas em multiprocessador de alimentos e, em seguida, foram liofilizadas em liofilizador de bancada (Liotop L101, Liobras Ind. Com. Serv. Liofilizadores Ltda.). Após liofilização, foram novamente trituradas (IKA A11), embaladas e armazenadas sob temperatura ambiente.

Para a pesquisa de isoflavonas, utilizou-se metodologia baseada na sua extração a $65^{\circ} \mathrm{C}$, com metanol:água (80:20), por duas horas em frascos fechados, sob agitação mecânica, seguida da saponificação com solução diluída de hidróxido de sódio e análise por cromatografia líquida de fase reversa, de acordo com o método 2001.10 da AOAC, com pequenas modificações na obtenção da curva padrão (AOAC, 2005). Os extratos foram filtrados para balão volumétrico utilizando-se papel de filtro Whatman $\mathrm{n}^{\circ} 6$, onde tiveram seu volume completado com metanol para $50 \mathrm{~mL}$.

Os extratos metanólicos de isoflavonas foram analisados por cromatografia líquida de alta eficiência (high performance liquid chromatography $=$ HPLC), mediante a injeção automática de alíquotas de $25 \mu \mathrm{L}$ em cromatógrafo líquido modular W600 (Waters, EUA), com detetor de arranjo de fotodiodos UV/VIS a 260nm (PDA 996, Waters, EUA) e coluna YMC $\mathrm{C}_{18} 4,6 \mathrm{~mm} \times 250 \mathrm{~mm}$ (YMC, Inc., EUA), em forno a $45^{\circ} \mathrm{C}$, controlados pelo software Empower (Waters, EUA). O sistema cromatográfico foi ajustado para eluição a $1,3 \mathrm{~mL}$ $\min ^{-1}$ e composição da fase móvel conforme gradiente da tabela 1. A fase móvel A consistiu de mistura de água:metanol:ácido acético $(88: 10: 2)$ e a fase móvel B consistiu de mistura de metanol:ácido acético (98:2).

Para o cálculo das concentrações de isoflavonas da soja, construiu-se uma curva de calibração com cinco pontos de concentração de proteína isolada de soja, em uma faixa de trabalho de $27,0 \mathrm{mg}$ a $150,8 \mathrm{mg}$. As médias foram comparadas estatisticamente pelo Teste de Tukey, ao nível de 5\% de significância.

$\mathrm{Na}$ figura 1, é apresentado o perfil cromatográfico obtido para os tratamentos adicionados de proteína isolada de soja. De acordo com os cromatogramas obtidos e correspondendo-os com os padrões de isoflavonas, verifica-se que as amostras com soja apresentaram seis picos correspondentes às agliconas daidzeína e genisteína com maiores intensidades, bem como aos glicosídeos dessas duas isoflavonas. Sua ordem de eluição corresponde à descrita na literatura, com os derivados da daidzeína eluindo antes dos derivados da genisteína (MELLENTHIN \& GALENSA, 1999). São observados, ainda, picos correspondentes à glicitina e gliciteína nos cromatogramas dos tratamentos com PIS, embora em menor intensidade.

Tabela 1 - Gradiente da fase móvel utilizada para determinação de isoflavonas da soja por cromatografia líquida de alta eficiência nas amostras de lombo suíno adicionado de proteína isolada de soja.

\begin{tabular}{cccc}
\hline Etapa & $\begin{array}{c}\text { Tempo } \\
\text { (minutos) }\end{array}$ & $\begin{array}{c}\text { Fase móvel A } \\
(\%)\end{array}$ & $\begin{array}{c}\text { Fase móvel B } \\
(\%)\end{array}$ \\
\hline 1 & 0 & 90 & 10 \\
2 & 30 & 40 & 60 \\
3 & 30,1 & 0 & 100 \\
4 & 35 & 0 & 100 \\
5 & 35,1 & 90 & 10 \\
6 & 45 & 90 & 10 \\
\hline
\end{tabular}

Fase móvel A: água:metanol:ácido acético (88:10:2); fase móvel B: metanol:ácido acético (98:2). 


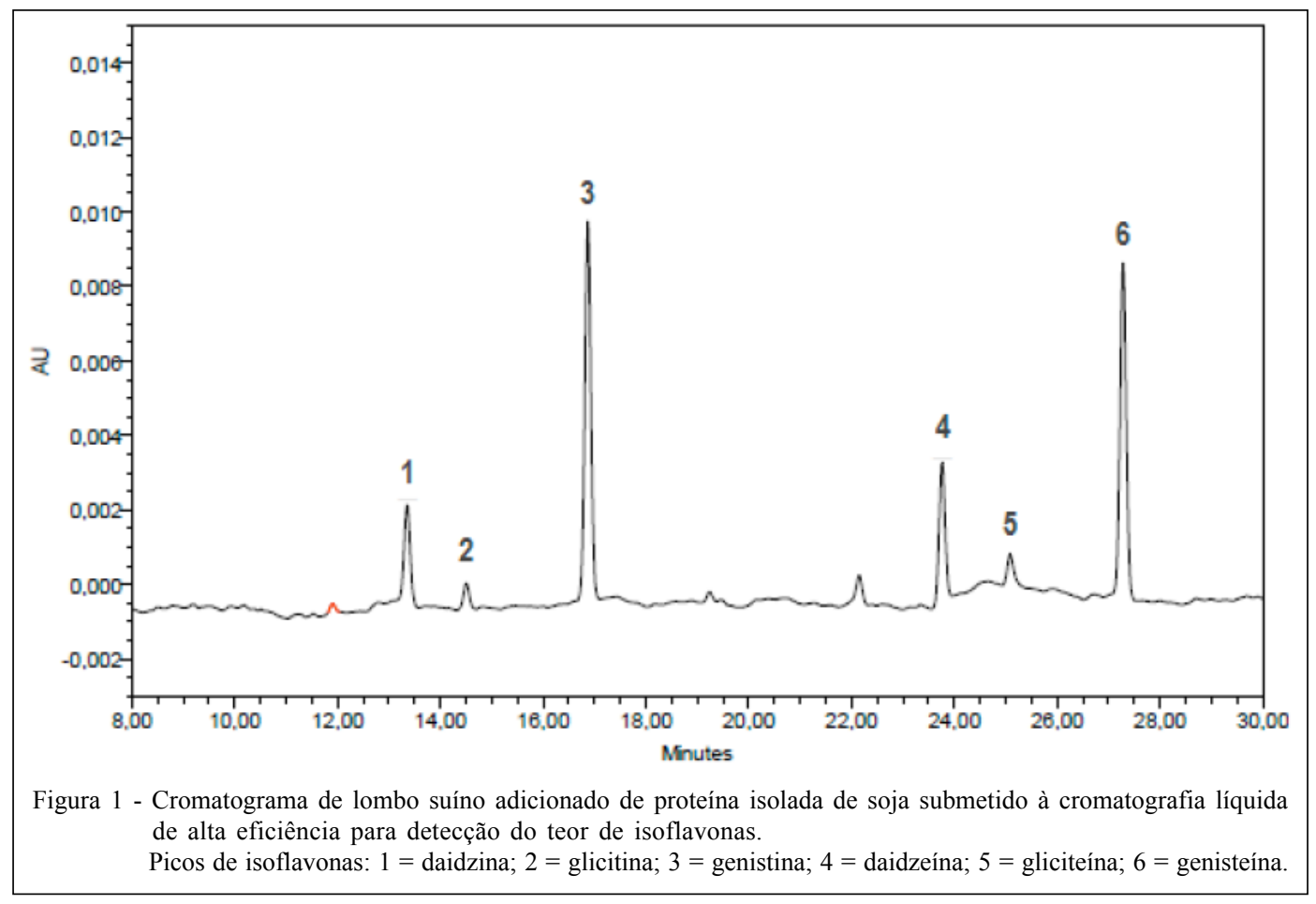

Na tabela 2, são apresentados os teores médios de isoflavonas detectados nas amostras de lombo, demonstrando que estas podem empregadas como indicadores da adição de soja em produtos cárneos. Como esperado, os tratamentos sem PIS não apresentaram picos de isoflavonas, enquanto os tratamentos com soja apresentaram isoflavonas em quantidades detectáveis por HPLC.

De acordo com GENOVESE \& LAJOLO (2001), a extração das isoflavonas com metanol $80 \%$ proporciona ótimo rendimento de extração e menor quantidade de picos contaminantes. A eficiência de extração provavelmente contribuiu para a qualidade dos cromatogramas, com picos simétricos e de boa resolução, sem picos interferentes, fazendo com que a técnica seja considerada de boa sensibilidade e especificidade para os fins pretendidos.

Elegeu-se o pico de genistina, por ser o de maior intensidade no perfil cromatográfico de isoflavonas desse ingrediente, para ser utilizado como marcador na amostras de lombo suíno. Considerando o valor médio de $73 \%$ para a umidade das amostras com PIS (tratamentos IV e VI), obtiveram-se, respectivamente, os valores de 1,79 e $1,23 \%$ de PIS

Tabela 2 - Teores médios de isoflavonas, expressos em $\mu \mathrm{g} 100 \mathrm{~g}^{-1}$ em base seca, detectados por cromatografia líquida de alta eficiência em amostras de lombo suíno adicionado de proteína isolada de soja.

\begin{tabular}{ccccccc}
\hline Tratamentos & Daidzina & $\begin{array}{c}\text { Glicitina } \\
(\mu \mathrm{g} / 100 \mathrm{~g})\end{array}$ & $\begin{array}{c}\text { Genistina } \\
(\mu \mathrm{g} / 100 \mathrm{~g})\end{array}$ & $\begin{array}{c}\text { Daidzeína } \\
(\mu \mathrm{g} / 100 \mathrm{~g})\end{array}$ & $\begin{array}{c}\text { Gliciteína } \\
(\mu \mathrm{g} / 100 \mathrm{~g})\end{array}$ & $\begin{array}{c}\text { Genisteína } \\
(\mu \mathrm{g} / 100 \mathrm{~g})\end{array}$ \\
\hline I & $\mathrm{ND}$ & $\mathrm{ND}$ & $\mathrm{ND}$ & $\mathrm{ND}$ & $\mathrm{ND}$ & $\mathrm{ND}$ \\
II & $\mathrm{ND}$ & $\mathrm{ND}$ & $\mathrm{ND}$ & $\mathrm{ND}$ & $\mathrm{ND}$ & $\mathrm{ND}$ \\
III & $\mathrm{ND}$ & $\mathrm{ND}$ & $\mathrm{ND}$ & $\mathrm{ND}$ & $\mathrm{ND}$ & $\mathrm{ND}$ \\
IV & $231,2^{\mathrm{a}}$ & $81,5^{\mathrm{a}}$ & $650,5^{\mathrm{a}}$ & $216,1^{\mathrm{a}}$ & $86,7^{\mathrm{nc}}$ & $260,7^{\mathrm{a}}$ \\
V & $\mathrm{ND}$ & $\mathrm{ND}$ & $\mathrm{ND}$ & $\mathrm{ND}$ & $\mathrm{ND}$ & $\mathrm{ND}$ \\
VI & $202,6^{\mathrm{b}}$ & $77,4^{\mathrm{a}}$ & $536,2^{\mathrm{b}}$ & $179,2^{\mathrm{b}}$ & $78,3^{\text {nc }}$ & $220,6^{\mathrm{b}}$ \\
VII & $\mathrm{ND}$ & $\mathrm{ND}$ & $\mathrm{ND}$ & $\mathrm{ND}$ & $\mathrm{ND}$ & $\mathrm{ND}$ \\
\hline
\end{tabular}

As médias seguidas pela mesma letra na vertical não diferem estatisticamente entre si $(\mathrm{P}>0,05) . \mathrm{nc}=$ não calculada. $\mathrm{ND}=$ não detectado.

Ciência Rural, v.40, n.4, abr, 2010. 
quantificados por cromatografia, corrigidos os valores da base seca (liofilizada) para base úmida e com base na curva-padrão construída com PIS $\left(\mathrm{R}^{2}=0,9996\right)$. Esses resultados demonstram que a técnica aplicada assegura a adequação dos produtos testados em relação ao limite legal $(2,0 \%)$, previsto no regulamento técnico para produtos elaborados com lombo suíno (BRASIL, 2000). Embora tenha havido variação significativa entre os tratamentos adicionados de soja $(\mathrm{P}<0,05)$, foram obtidos valores próximos ao valor de soja adicionado às amostras. No processo de injeção, existe sempre uma variação na quantidade de ingredientes incorporados à carne, causada por fatores intrínsecos e extrínsecos. A quantidade de $1,5 \%$ de proteína não cárnea estimada para os produtos em análise considera a retenção de toda a salmoura injetada. Variações nessa quantidade, detectadas por técnicas analíticas, provavelmente indicam variação na quantidade de salmoura retida pela carne.

Com a utilização de HPLC, foi possível detectar a PIS pela determinação do teor de isoflavonas, sendo obtidos valores próximos ao valor adicionado nas formulações de lombo suíno injetado $(1,5 \%)$, sem sofrer interferência dos outros ingredientes utilizados no experimento. A técnica se revelou como uma alternativa rápida e de fácil execução, devendo ser estudada em outros produtos cárneos para a efetiva implementação do controle da utilização desse ingrediente.

\section{REFERÊNCIAS}

AOAC - ASSOCIATION OF OFFICIAL ANALYTICAL CHEMISTS. Method 2001.10. Determination of isoflavones in soy and selected foods containing soy. Official Methods of Analysis of AOAC International. 18.ed. Gaithersburg: AOAC International, 2005. 1141p.

BRASIL. MINISTÉRIO DA AGRICULTURA E DO ABASTECIMENTO. Instrução Normativa n.21, de 31/07/2000 (anexo III). Regulamento técnico de identidade e qualidade de lombo. Diário Oficial da União, seção I, p.12, 2000.

CESAR, I.C. et al. Determinação de daidzeína, genisteína e gliciteína em cápsulas de isoflavonas por cromatografia em camada delgada (CCD) e cromatografia líquida de alta eficiência (CLAE). Revista Brasileira de Farmacognosia, v.17, n.4, p.616-625, 2007. Disponível em: <http://www.scielo.br/pdf/ rbfar/v17n4/a22v17n4.pdf>. Acesso em: 15 set. 2009. doi: 10.1590/S0102-695X2007000400022.

DAGUER, H. et al. Perfil eletroforético de lombo suíno adicionado de proteínas não cárneas. Ciência Rural, v.40, n.2, p. 434-440, 2010. Disponível em: <http://www.scielo.br/ $\mathrm{pdf} / \mathrm{cr} / 2010 \mathrm{nahead} / \mathrm{a} 459 \mathrm{cr} 2045 . \mathrm{pdf}>$. Acesso em: 01 fev. 2010. doi: $10.1590 / \mathrm{S} 0103-84782010005000011$.

GENOVESE, M.I.; LAJOLO, F.M. Determinação de isoflavonas em derivados de soja. Ciência e Tecnologia de Alimentos, v.21, n.1, p.86-93, 2001. Disponível em: <http://www.scielo.br/ $\mathrm{pdf} / \mathrm{cta} / \mathrm{v} 21 \mathrm{n} 1 / 5371 . \mathrm{pdf}>$. Acesso em: 15 set. 2009 . doi: 10.1590/S0101-20612001000100019.

KUHNLE, G.G. et al. Phytoestrogen content of foods of animal origin: dairy products, eggs, meat, fish, and seafood. Journal of Agricultural and Food Chemistry, v.56, n.16, p.73117315, 2008. Disponível em: <http://pubs.acs.org/doi/pdfplus/ 10.1021/jf801534g>. Acesso em: 15 set. 2009. doi: 10.1021/ jf801534g.

MELLENTHIN, O.; GALENSA, R. Analysis of polyphenols using capillary zone electrophoresis and HPLC: detection of soy, lupin, and pea protein in meat products. Journal of Agricultural and Food Chemistry, v.47, n.2, p.594-602, 1999. Disponível em: <http://pubs.acs.org/doi/pdf/10.1021/ jf980749h>. Acesso em: 15 set. 2009. doi: 10.1021/jf980749h. 